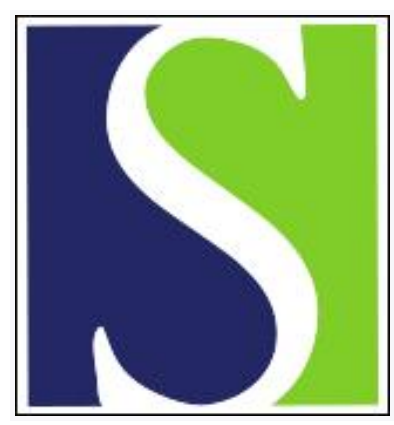

Scand J Work Environ Health 1991;17(6):425-429

https://doi.org/10.5271/sjweh.1679

Issue date: Dec 1991

Comparison of methods for the assessment of postural load on the back.

by Burdorf A, Laan J

Affiliation: Institute of Occupational Health, Erasmus University Rotterdam, The Netherlands.

This article in PubMed: www.ncbi.nlm.nih.gov/pubmed/1838618

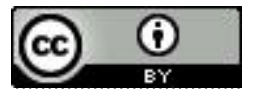




\title{
Comparison of methods for the assessment of postural load on the back
}

\author{
by Alex Burdorf, MSc, Judith Laan, MD ${ }^{1}$
}

\begin{abstract}
BURDORF A, LAAN J. Comparison of methods for the assessment of postural load on the back. Scand $J$ Work Environ Health 1991;17:425-9. A questionnaire, a self-administered log, and an observational method were simultaneously applied in the workplace of 35 mechanical repair men to assess exposure to strenuous postures and movements of the back. The average duration of time spent in a standing position was considerably underrated by the workers, while the duration of sitting was strongly overrated when compared with the ratings obtained with the observational method. The workers' ratings of duration with a bent or rotated trunk was two to four times lower than the observed duration. The estimate of the average number of lifts performed per hour was more than four times higher in the questionnaire than in the log. The same striking difference was found for the frequency of bending or rotating of the trunk. These results suggest that the reliability of questionnaire methods for the assessment of postural load in epidemiologic studies is probably not very high.
\end{abstract}

Key terms: measurement, postural load, questionnaire, reliability.

Musculoskeletal disorders are a major source of morbidity in many industrial populations. Back pain is one of the most common reasons for time loss through sick leave $(1,2)$. In many occupational situations studies are undertaken to provide a basis for the risk assessment of the development of back pain. Although a variety of pathogenetic mechanisms may affect different spinal structures, it is widely accepted that mechanical loads on the spine, in particular as a result of occupational activities, may cause low-back pain $(3,4)$. The impact of mechanical loads on the spine is difficult to assess in occupational (epidemiologic) studies. A quantitative description of exposure to mechanical loads in occupational situations has many methodological difficulties and limitations (5). Therefore alternative approaches based upon simplified methods to document ergonomic exposures are required.

However, most studies on occupational populations lack any model for the quantification of postural load on the back. In many of these studies the assessment of exposure to risk factors for back pain was restricted to broad occupational titles or job categories (6). In some studies the presence or absence of specific risk factors, such as lifting, bending, twisting, and prolonged standing and sitting, was evaluated by dichotomous responses, while in others exposures to risk factors were measured by scaled parameters rating subjective responses from, for example, "never" to "always." A more quantitative description of ergonomic exposures, based on detailed information on the frequency and duration of specific postures and move-

\footnotetext{
1 Institute of Occupational Health, Erasmus University Rotterdam, Rotterdam, The Netherlands.
}

Reprint requests to: Mr A Burdorf, Institute of Occupational Health, Erasmus University Rotterdam, Medical Faculty, PO Box 1738, 3000 DR Rotterdam, The Netherlands. ments, is relatively sparse. Quantitative objective measures of exposure to postural load have rarely been employed in occupational studies $(5,7)$.

Regarding the limited scope of most measures of exposure to postural load on the back, it can be expected that their validity and reliability in epidemiologic studies is rather poor and subsequently easily lead to a misclassification of exposure. For this reason, a pilot study was conducted to explore the differences in some commonly used techniques for the assessment of postural load on the back. The study compared two methods of workers' ratings of postural load with a more quantitative observational method. The aims of this study were (i) to evaluate the agreement between the three methods for assessing postural load on the back and (ii) to determine the extent to which disagreement is likely to be influenced by the individual characteristics of the subjects in the study population and their work conditions.

\section{Subjects and methods}

\section{Subjects}

The study was carried out in a maintenance and repair department of a steel factory. The study population originally consisted of 41 workers who participated in the questionnaire part of this study. It was not possible to perform observations on three workers (because of holidays), and another three workers kept a $\log$ with insufficient data. The remaining 35 workers performed several tasks. The following task groups could be distinguished: (i) seven pipe fitters, (ii) seven mechanical repair men, (iii) six constructional fitters, and (iv) 15 benchmen.

The subjects ranged in age between 22 and 57 (mean 44 , SD 10) years. The mean height and weight were 
179 (SD 8) $\mathrm{cm}$ and 79 (SD 11) kg, respectively. The subjects' mean work experience was 17 (SD 9) years in their present job.

\section{Methods for assessing exposure}

Three different methods for assessing exposure to postural load on the back were selected. Each procedure aimed at collecting information on the frequency and duration of specific movements and postures during normal work.

The first method was based on a questionnaire about the subjective work load of the subject's present job. The work load was evaluated by questions regarding the duration and frequency of basic work postures and movements, lifting activities, and specific movements of the lower back during activities on an average workday of the past week. The questions concerning standing, walking, sitting, and kneeling were phrased as: "How many hours do you have to stand on an average workday?" Lifting activities were evaluated by questions regarding how much of the workday the individual lifted or carried loads, how many times per hour these activities were performed, and how much the average load weighed. Information on trunk posture was elicited by the question: "How many hours do you have to work with a bent or twisted trunk on an average workday?" The frequency of trunk bends and twists was obtained with a question similar to the question on the frequency of lifting activities. Questions were also included on personal characteristics such as age, height and weight, and work experience. This approach has recently been used, for example, in studies among nurses $(8,9)$. A second questionnaire was used to obtain information on complaints of back, neck, or shoulder pain within the past 12 months (10). Both questionnaires were administered by a physician at the on-site medical service.

The second method was based on a log including the same questions as the questionnaire on duration and frequency of postures and movements during work activities. Each worker had to keep this log for one workday and had to answer the questions every hour regarding his postural load during the preceding hour. This method was selected to avoid recall bias with respect to the subjects' judgments of their postural loads.

The third method was the Ovako working posture analyzing system (OWAS) for identifying and evaluating poor work postures (11). The positions of the lower back and the lower limbs were observed and recorded according to the 84 different postures distinguished by this method. Trunk postures with flexion or rotation of more than 20 degrees from a straight, neutral position were classified as hending of the trunk. The position and movement of t.1e lower limbs was used to distinguish between standing, walking, sitting, and kneeling/squatting. After the specific work tasks were identified for each separate job, the workers were observed during two periods of $10 \mathrm{~min}$ covering all the important work tasks. The recording procedure con- sisted of 60 observations of every worker, at intervals of $20 \mathrm{~s}$. This sampling method was sufficient to include all of the relevant activities. All of the observations were performed on the same day that the worker had to keep a log so that confounding by day-to-day fluctuations in the subjects' work conditions could be avoided when the OWAS method was compared with the subjects' ratings in the log. The observations were made by the same observer. The observation data can be used to calculate the average percentage of time spent in defined work postures and movements during a workday. Recent examples of similar approaches have been published by several research groups (12-14).

The study took place over a period of three weeks. The investigation started with the recruitment of workers. Each worker was interviewed for information on specific aspects of their postural load during work (method 1). During the following two weeks they were asked to keep the log for one workday (method 2). On the same day the observational method was performed (method 3). The measures of exposure in the three selected methods for the assessment of postural load on the lower back are summarized in table 1 . For reasons of comparability parameters on the duration of time recorded in the questionnaire and the log have been converted from hours per workday to percentage of daily worktime. Since there were some minor differences among the parameters of postural load in each method, some parameters were measured only by two methods.

\section{Statistical methods}

The null hypothesis that the mean of the differences between pairs of continuously distributed parameters does not significantly differ from zero was tested with the two-tailed paired t-test. An analysis of variance was used to determine the influence of categorical variables (eg, task group and presence of musculoskeletal complaints) on the workers' ratings and the observations. Since the parameters of exposure were measured at intervals, measures of agreement for qualitative data such as Cohen's kappa were not applicable. Therefore, a multiple regression analysis was performed to describe the extent, direction, and strength of the correlation between the parameters derived from two different methods. The workers' assessments were used as independent variables and the measurements of the observational method were considered the dependent variables. The rationale behind this choice was that we were interested in whether the workers' subjective assessments could predict the more objective observations. A significant regression coefficient indicates that two parameters are associated linearly. A significant intercept indicates the existence of a systematic difference between two parameters, whose absolute value depends on the value of the independent variable. The strength of the linear relationship between two parameters, expressed by the propor- 
tion of variance explained, can be regarded as a measure of agreement between the workers' ratings and the observations carried out.

\section{Results}

The questionnaire on health complaints revealed that the 12-month prevalences of pain of the back, the neck, and the shoulder among the workers were 46,34 , and $34 \%$, respectively.

The overall results of the workers' assessments and of the observations on duration and frequency of work postures and movements are summarized in table 1. For most of the postures and movements significant differences were observed. The average duration of time spent in a standing position was underrated by the workers, while the duration of sitting was overrated. The most striking difference appeared in the estimated duration of lifting and/or carrying loads during a workday. As shown in this table, the estimates of the average number of lifting activities were much higher in the questionnaires than in the logs. The same result was found for the frequency of bending and/or rotating of the trunk. Large standard deviations were found for all postures and movements, regardless of the method of assessment.

In the analysis of variance dichotomous variables for the four different task groups were far from significant. The variance in the workers' ratings in the questionnaire and the $\log$, as well as the variance in the observed aspects of postural load, could not be explained by differences in the work conditions among the four task groups. Therefore the study population of 35 workers can be regarded as a uniform sample of workers, performing different activities as part of their job.

Multiple regression analyses were conducted to investigate whether the workers' ratings could be used as a suitable predictor for the observed postures and movements. The results of the (age-adjusted) regression analyses, presented in table 2 , demonstrate that the proportion of variance explained by the questionnaire method was low for each parameter. The workers' ratings in the log resulted in a much better fit for the observed period of time in standing and sitting positions. For kneeling/squatting and trunk bending significant regression coefficients were found although the proportions of variances explained were not very high. In each regression model the role of potential confounders was investigated. Neither personal characteristics such as age, height, and weight nor duration of employment in the job showed any significant influence on the relationships between the workers' ratings and the observed postures and movements.

In general, the health status of the workers did not influence their ratings of postural load. Workers with low-back pain and workers with shoulder pain usually reported the same distribution of strenuous work postures and movements as workers without these complaints. However, in the regression analysis on the predictive power of workers' ratings in the logs for the observed duration of time with a bent trunk, significant contributions were observed for dichotomous variables of low-back pain $(\beta=-10.8, P<0.05)$ and shoulder pain $(\beta=14.6, P<0.05)$. Workers with lowback pain judged their duration of trunk bending postures during an average workday to be lower than workers without low-back pain, whereas for workers with shoulder pain the opposite result was found. When both complaints were taken into account in the regression model, the proportion of variance explained increased from 18 to $37 \%$.

\section{Discussion}

The workers' estimates of duration and frequency of specific work postures and movements showed con-

Table 1. Results of the assessment of exposure to postural load on the back. (OWAS = Ovako working posture analyzing system)

\begin{tabular}{|c|c|c|c|c|c|c|c|c|c|c|c|c|c|c|c|c|c|c|}
\hline \multirow{3}{*}{ Method } & \multicolumn{8}{|c|}{ Basic postures and movements } & \multicolumn{6}{|c|}{ Lifting } & \multicolumn{4}{|c|}{ Trunk bending } \\
\hline & \multicolumn{2}{|c|}{$\begin{array}{c}\text { Standing } \\
\left.(\%)^{a}\right)\end{array}$} & \multicolumn{2}{|c|}{$\begin{array}{c}\text { Walking } \\
\left(\%^{2}\right)\end{array}$} & \multicolumn{2}{|c|}{$\underset{\left(\%^{2}\right)}{\text { Sitting }}$} & \multicolumn{2}{|c|}{$\begin{array}{l}\text { Kneeling/ } \\
\text { squatting } \\
\left(\%{ }^{a}\right)\end{array}$} & \multicolumn{2}{|c|}{$\begin{array}{c}\text { Duration of } \\
\text { lifting } \\
\text { and/or } \\
\text { carrying } \\
\left(\% \%^{a}\right)\end{array}$} & \multicolumn{2}{|c|}{$\begin{array}{c}\text { Frequency of } \\
\text { lifting } \\
\text { and/or } \\
\text { carrying } \\
\text { (Nb) }\end{array}$} & \multicolumn{2}{|c|}{$\begin{array}{l}\text { Weight of } \\
\text { load } \\
\left(\mathrm{kg}^{\mathrm{c}}\right)\end{array}$} & \multicolumn{2}{|c|}{$\begin{array}{c}\text { Duration of } \\
\text { time of } \\
\text { postures } \\
\text { with for- } \\
\text { ward in- } \\
\text { clination } \\
\text { and/or } \\
\text { rotation of } \\
\text { the trunk } \\
\left.(\%)^{a}\right)\end{array}$} & \multicolumn{2}{|c|}{$\begin{array}{l}\text { Frequency of } \\
\text { bending } \\
\text { and/or } \\
\text { rotating of } \\
\text { the trunk } \\
\left(\mathrm{N}^{\mathrm{b}}\right)\end{array}$} \\
\hline & Mean & SD & Mean & SD & Mean & SD & Mean & SD & Mean & SD & Mean & $\mathrm{SD}$ & Mean & $\mathrm{SD}$ & Mean & SD & Mean & SD \\
\hline $\begin{array}{l}\text { Questionnaire } \\
(\mathrm{N}=35)\end{array}$ & 38 & $17^{\star}$ & 29 & $10^{*}$ & 16 & $9^{*}$ & 13 & 10 & 4 & $3^{*}$ & 11.3 & $10.9 * 1$ & 12.1 & 8.9 & 22 & $14^{*}$ & 24.1 & $27.4^{* 1}$ \\
\hline $\log (N=35)$ & 37 & $15^{*}$ & 24 & 10 & 28 & $16^{*}$ & 10 & 8 & . & $\cdot$ & 2.7 & 2.4 & 12.8 & 9.1 & 11 & $8^{*}$ & 4.8 & 5.6 \\
\hline $\begin{array}{l}\text { OWAS method } \\
(\mathrm{N}=35)\end{array}$ & 58 & 18 & 24 & 14 & 4 & 9 & 14 & 12 & 37 & 25 & $\cdot$ & . & . & ' & 40 & 18 & . & . \\
\hline
\end{tabular}

a Percentage of daily worktime.

- Average number per hour.

- Average weight of load in kilograms.

* $P<0.05$ (two-tailed paired $t$-test with the OWAS method as the reference); ${ }^{* 1} \mathrm{P}<0.05$ (two-tailed paired t-test with the log method as the reference). 
Table 2. Linear regression with the observed postures and movements as the dependent variables and the workers' assessments of these postures and movements as the independent variables.

\begin{tabular}{|c|c|c|c|c|c|c|}
\hline \multirow[b]{2}{*}{ Parameter } & \multicolumn{3}{|c|}{ Questionnaire } & \multicolumn{3}{|c|}{$\log$} \\
\hline & $\begin{array}{c}\text { Intercept } \\
\beta_{0}\end{array}$ & $\begin{array}{l}\text { Posture } \\
\beta_{1}\end{array}$ & $\begin{array}{l}\text { Explained } \\
\text { variance } \\
\mathbf{R}^{2}\end{array}$ & $\begin{array}{c}\text { Intercept } \\
\beta_{0}\end{array}$ & $\begin{array}{l}\text { Posture } \\
\beta_{1}\end{array}$ & $\begin{array}{l}\text { Explaineo } \\
\text { variance } \\
\qquad \mathrm{R}^{2}\end{array}$ \\
\hline \multicolumn{7}{|l|}{ Basic postures and movements } \\
\hline $\begin{array}{l}\text { Standing ( } \% \text { of daily worktime) } \\
\text { Walking ( } \% \text { of daily worktime) } \\
\text { Sitting ( } \% \text { of daily worktime) } \\
\text { Kneeling/squatting ( } \% \text { of daily worktime) }\end{array}$ & $\begin{array}{l}43.9^{* *} \\
13.5 \\
-1.6 \\
10.2^{\star *}\end{array}$ & $\begin{array}{l}0.37^{*} \\
0.35 \\
0.36^{\star} \\
0.30\end{array}$ & $\begin{array}{r}11 \% \\
6 \% \\
14 \% \\
5 \%\end{array}$ & $\begin{array}{c}32.5^{* *} \\
18.5^{* *} \\
-4.9^{*} \\
8.0^{*}\end{array}$ & $\begin{array}{l}0.68^{* *} \\
0.24 \\
0.33^{\star *} \\
0.61^{\star}\end{array}$ & $\begin{array}{r}33 \% \\
2 \% \\
40 \% \\
15 \%\end{array}$ \\
\hline \multicolumn{7}{|l|}{ Lifting } \\
\hline $\begin{array}{l}\text { Duration of lifting and/or carrying } \\
\text { (\% of daily worktime) }\end{array}$ & $24.8^{\star *}$ & $3.33^{\star}$ & $12 \%$ & & & \\
\hline \multicolumn{7}{|l|}{ Trunk bending } \\
\hline $\begin{array}{l}\text { Duration of time of postures with forward } \\
\text { inclination and/or rotation of the trunk } \\
\text { ( } \% \text { of daily worktime) }\end{array}$ & $32.1^{* *}$ & 0.34 & $7 \%$ & $29.6^{* *}$ & $0.93^{*}$ & $18 \%$ \\
\hline
\end{tabular}

* $P<0.05, * * P<0.01$.

siderable variations. The variance in the ratings of the workers in the questionnaire and the log could not be explained by differences between the four task groups among the personnel of the maintenance and repair department. The between-task variability mainly accounted for less than $10 \%$ of the exposure variance, a finding which indicates that the within-task variability was much greater than the between-task variability. The same results were found for the assessments based on the observation technique. Therefore, it is not likely that differences in the work conditions among the four task groups accounted for the considerable variations in the exposure assessments.

The question then arises of how the exposure variance might be explained. Personal characteristics like age and height and the work history in total years of employment did not influence the workers' ratings or the observed postures and movements. It has been postulated that workers' assessments of exposure could be influenced by the existence of musculoskeletal pain either because workers with pain might learn to do their jobs in a way that minimizes biomechanical load in order to alleviate symptoms or to avoid their aggravation (7) or that subjects with back pain are more sensitive to tasks which entail heavy lifting and frequent bending and rotating of the trunk (3). In this study the three methods showed no significant differences for work postures and movements between workers with musculoskeletal pain and those without, except for the workers' ratings of daily worktime with a bent or twisted trunk in the log. This association could not be reproduced for the workers' ratings of the same parameter in the questionnaire or for any other parameter in the questionnaire, the log, or the observations. The presence of response bias due to complaints of the back, neck, or shoulder could not be proved.

Another source of variability in the measures of exposure may have been a lack of precision (ie, reliability). Since repeated measurements were not per- formed, this hypothesis cannot be tested. However, the results in table 2 suggest that the reliability of the questionnaire and log methods for measuring specific aspects of postural load will probably not be very high. When the OWAS observation method is regarded as an instrument capable of measuring true exposure, both questionnaire instruments lacked validity for assessing exposure. Although there were significant associations between the workers' ratings and the observations, the proportions of variances explained were low. The calculated values of the intercepts in the regression models expressed large systematic differences in the data obtained by the self-administered methods and the direct observation method.

The workers severely underestimated the average time spent in a posture with a bent or twisted trunk. Rossignol \& Baetz (15) also found that the agreement between self-administered questionnaires by employees and direct observation by investigators was poor for the perception of bending and twisting of the trunk. These results indicate that workers cannot be expected to evaluate accurately nonneutral postures when defined in terms of degrees of deviation. Thus the poor agreement between the questionnaire and observational methods on this parameter may have been the result of the incomparability of the two methods.

Other parameters may be expressed more accurately in questionnaires, for example, the duration of lifting and/or carrying loads. In this study a striking difference appeared in the average duration of the lifting or carrying of objects during a workday. In one study a complementary observation has been reported (6). The authors stated that only for $10 \%$ of the workers were the questionnaire and observational methods consistent regarding both the weight and frequency of the material handled. Although basic postures like standing, walking, and kneeling are easily defined, significant underestimation by workers was also present for these parameters in our study. This finding suggests that accurate measurement of basic postures in 
questionnaires may be difficult. In a study among nurses some contradictory results have been described (16). Workers' estimates of the average time spent sitting versus standing or walking during a workday closely agreed with those of the observers, whereas reports on the time spent in other activities (eg, kneeling) were less reliable (16).

Since the OWAS method was applied as a multimoment technique, no comparisons can be made for the parameters of frequency. The comparison of the workers' ratings in the questionnaire and the log showed significant differences for the frequency of lifting activities and trunk bending. Workers recalled these risk factors more thoroughly in the questionnaire, a finding which demonstrates that the assessment of exposure depends on the method of administration.

One might question the appropriateness of the observation technique as a reference. The observations were only two 10 -min samples of much longer work periods in which tasks could vary with unknown frequency. Since this technique is time-consuming and costly for observing and analyzing a large number of jobs, the sampling period was an economic and practical choice. Observation during a period of $8 \mathrm{~h}$ would have enhanced the agreement between the observational method and the log on an individual level. Consequently, the proportion of variance explained would have been higher. However, on a group level, the significant differences in the mean values of certain risk factors would not have disappeared with a longer sampling period. The mean score of the OWAS method for a specific risk factor is based upon 2100 observations (nearly $12 \mathrm{~h}$ ) during a period of two weeks, which is likely to be sufficient for estimating the true exposure to the risk factor in a uniform sample of workers. Even though this method only provided limited information on specific aspects of postural load on an individual level, it was regarded as adequate for the purpose of the study.

Although the small number of workers limits interpretation, the results of this study suggest that the use of exposure information based on self-reported aspects of postural load on the back is probably not very reliable. In this study the consistency of the workers' ratings with an observational technique was rather poor. Therefore, it can be argued that questionnaires for assessing postural load are not viable tools with which to classify the postural load of workers. Considerable misclassification is inevitable when questionnaire data are used to assign exposure categories for subjects in epidemiologic studies. Since the misclassification of exposure is always in the direction of the zero value (17), relationships between postural load and musculoskeletal disorders will systematically be underestimated. It is obvious that inconclusive doserelated risk estimates on musculoskeletal disorders must be interpreted with great care.

This study underlines the statement made by several authors that the challenge to develop valid and prac- tical techniques for assessing exposure to postural load is still open $(5,6,7)$.

\section{Acknowledgments}

The authors wish to thank Dr S van Wingerden, occupational physician in the steel industry, for his valuable contribution to the organization of this study.

\section{References}

1. Snook SH. Low-back pain in industry. In: White AA, Gordon SL, ed. Symposium on idiopathic low-back pain. St Louis, MO: Mosby Company, 1982:23-38.

2. Troup JDG. Causes, prediction and prevention of back pain at work. Scand J Work Environ Health 1984;10: 419-28.

3. Walsh K, Varnes N, Osmond C, Styles R, Coggon C. Occupational causes of low-back pain. Scand J Work Environ Health 1989;15:54-9.

4. Lindh M. Biomechanics of the lumbar spine. In: Nordin M, Frankel VH, ed. Basic biomechanics of the musculoskeletal system. Philadelphia/London: Lea \& Febiger, 1989:183-207.

5. Westgaard RH. Measurement and evaluation of postural load in occupational work situations. Eur J Appl Physiol 1988;57:291-304.

6. Hagberg M. Occupational musculoskeletal disorders a new epidemiological challenge? In: Hogstedt C, Reuterwall C, ed. Progress in occupational epidemiology. Amsterdam: Excerpta Medica, 1988:15-26.

7. Punnett L, Keyserling WM. Exposure to ergonomic stressors in the garment industry: application and critique of job-site work analysis methods. Ergonomics 1987;30:1099-116.

8. Estryn-Behar M, Kaminski M, Peigne E, et al. Strenuous working conditions and musculo-skeletal disorders among female hospital workers. Int Arch Environ Health 1990;62:47-57.

9. Jensen RC. Back injuries among nursing personnel related to exposure. Appl Occup Environ Hyg 1990;5: $38-45$.

10. Kuorinka I, Jonsson B, Kilbom A, et al. Standardised Nordic questionnaires for the analysis of musculoskeletal symptoms. Appl Ergon 1987;18:233-7.

11. Karhu O, Kansi P, Kuorinka I. Correcting working postures in industry: a practical method for analysis. Appl Ergon 1977;8:199-201.

12. Keyserling WM, Punnett L, Fine LJ. Trunk posture and back pain: identification and control of occupational risk factors. Appl Ind Hyg 1988:3;87-92.

13. Leino P, Hasan J, Karppi S-L. Occupational class, physical workload, and musculoskeletal morbidity in the engineering industry. $\mathrm{Br} \mathrm{J}$ Ind Med 1988:45;672-81.

14. Ryan AG. The prevalence of musculo-skeletal symptoms in supermarket workers. Ergonomics 1989;32:359—71.

15. Rossignol M, Baetz J. Task-related risk factors for spinal injury: validation of a self-administered questionnaire on hospital employees. Ergonomics 1987;30: $1531-40$.

16. Baty D, Buckle PN, Stubbs DA. Posture recording by direct observation, questionnaire assessment and instrumentation: a comparison based on a recent field study. In: Corlett N, Wilson J, ed. The ergonomics of working postures. London: Taylor and Francis, 1986: $283-92$.

17. Rothman KJ. Modern epidemiology. Boston, MA: Little, Brown and Company, 1986.

Received for publication: 14 January 1991 